\title{
PENGEMBANGAN BUKU PENGAYAAN FISIKA KELAUTAN BERBASIS AUGMENTED REALITY UNTUK MENINGKATKAN KEMAMPUAN BERPIKIR KRITIS
}

\author{
Syifa Nabila Basyir ${ }^{\text {a) }}$, Cecep E. Rustana ${ }^{\text {b) }}$, Firmanul Catur Wibowo ${ }^{\text {c) }}$ \\ Program Studi Pendidikan Fisika, Universitas Negeri Jakarta, Jalan Rawamangun Muka No 1. Jakarta Timur, \\ 13220, Indonesia \\ Email: ${ }^{\text {a) }}$ syifanbila75@gmail.com, ${ }^{\text {b) }}$ crustana@unj.ac.id, ${ }^{\mathrm{c})} \mathrm{fcwibowo} @$ unj.ac.id
}

\begin{abstract}
Abstrak
Empat tahun terakhir, pengetahuan tentang laut tidak memiliki porsi yang cukup dalam kurikulum Indonesia meskipun kita tahu bahwa dua pertiga bagian Indonesia terdiri dari laut. Oleh karena itu, penelitian ini bertujuan untuk menghasilkan buku pengayaan fisika kelautan berbasis augmented reality yang dapat digunakan untuk meningkatkan keterampilan berpikir kritis pesertadidik. Penelitian ini dikembangkan dengan menggunakan berbagai tahapan Formative Development Method (FODEM). Hasil penelitian ini menunjukkan bahwa buku ini dapat memunculkan objek tentang fisika di bidang kelautan lebih jelas dengan teknologi augmented reality. Jadi, buku ini dapat meningkatkan keterampilan berpikir kritis siswa secara signifikan. Melalui proses validasi oleh para ahli dan pengujian peserta didik, buku pengayaan fisika kelautan berbasis augmented reality ini dapat digunakan untuk meningkatkan keterampilan berpikir kritis peserta didik.
\end{abstract}

Kata-kata kunci: Buku Pengaan Fisika Kelautan, Augmented Reality, Kemampuan Berpikir Kritis.

\begin{abstract}
The last four years, the knowledge about the sea lacks a sufficient portion in Indonesian curriculum even though we know that two-thirds part of Indonesia consists of the sea. Therefore, this research aims to produce physics book of marine based on augmented reality that can be used to improve students' critical thinking skills. This research was developed using various stages of Formative Development Methods (FODEM). The results of this research show that the book can bring up objects about physics in the marine field more clearly with augmented reality technology. So, this book can improve students' critical thinking skills significantly. Through the process of validation by experts and testing of students, this physics book of marine based on augmented reality can be used to improve students' critical thinking skills.
\end{abstract}

Keywords: Physics Book of Marine, Augmented Reality, Critical Thinking Skills 


\section{PENDAHULUAN}

Perkembangan ilmu pengetahuan dan teknologi yang pesat memberikan perubahan yang signifikan terhadap perkembangan proses pembelajaran. Hal ini mendorong pendidik melakukan inovasi dalam pembelajaran, salah satunya dalam penggunaan media pembelajaran sebagai salah satu upaya untuk meningkatkan kualitas pendidikan [1]. Pada pembelajaran fisika ditemukan bahwa kemampuan kognitif dan keterampilan berpikir kritis siswa masih tergolong rendah [2]. Hal ini berarti masih banyak siswa yang sulit menguasai kemampuan kognitif dan keterampilan berpikir kritis [3]. Selain itu, kehidupan di abad ke-21 menuntut peserta didik untuk menguasai berbagai keterampilan salah satunya keterampilan berpikir kritis [4].

Abad ke-21 menuntut siswa untuk untuk menguasai berbagai keterampilan salah satunya dalam dapat mengembangkan media [5]. Namun sayangnya, minat baca di Indonesia tergolong rendah. Rendahnya minat baca masyarakat Indonesia salah satunya dipengaruhi oleh kurang menariknya buku-buku yang beredar di kalangan masyarakat Indonesia. Buku tidak hanya menyajikan informasi tetapi buku juga harus bisa membimbing berpikir konstruktif, mengarahkan kreativitas, menumbuhkan sikap moral, sosial, dan agama yang baik dan bisa menuntut ke arah kehidupan yang mandiri [6]. Selain itu, salah satu ciri buku yang baik adalah memuat ilustrasi yang dapat membantu peserta didik belajar. Ilustrasi tersebut dapat berupa gambar, bagan, dan lain sebagainya [7].

Ada dua macam jenis buku yaitu buku teks pelajaran, sebagai acuan wajib, dan buku non-teks pelajaran. Selain buku teks pelajaran yang menjadi acuan wajib, adapula buku non-teks yang merupakan buku-buku yang tidak digunakan secara langsung sebagai buku untuk mempelajari suatu ilmu pengetahuan, salah satunya adalah buku pengayaan. Buku pengayaan dapat digunakan sebagai buku bacaan peserta didik, pendidik, pengelola pendidikan, dan masyarakat lainnya sehingga dapat memperkaya dan meningkatkan penguasaan IPTEK [8].

Dunia pendidikan saat ini dituntut untuk melakukan inovasi dan kreativitas yang bertujuan agar dapat meningkatkan keefektifan dalam pembelajaran dan mutu pendidikan, yaitu dapat dengan cara menggunakan Augmented Reality [9, 10]. Salah satu kelebihan dari Augmented Reality ini adalah ia memiliki visual yang menarik, karena dapat menampilkan objek 3D yang tadinya abstrak menjadi seakan-akan ada pada lingkungan nyata [11, 12]. Metode Augmented Reality juga memiliki kelebihan dari sisi interaktif karena menggunakan marker atau penanda untuk menampilkan objek 3D tertentu yang di arahkan ke kamera. Teknologi Augmented Reality juga dapat mendukung pembelajaran dengan HOTS (high order thinking skills) [13, 14]. Selain menggunakan Augmented Reality, objek 3D bisa ditampilkan dengan menggunakan e-modul [15]

Fisika merupakan ilmu yang mengkaji interaksi antara energi dan materi, merupakan dasar dari ilmu pengetahuan alam yang didapatkan dari hasil eksperimen dan pengembangan teori [16]. Fisika merupakan salah satu cabang ilmu pengetahuan alam yang dapat menjelaskan seluruh fenomena yang terjadi pada kehidupan di alam semesta ini, termasuk salah satunya dalam bidang kelautan. Namun, selama ini pengetahuan tentang laut tidak mendapat porsi yang cukup dalam kurikulum pendidikan sekolah [17]. Tidak ada mata pelajaran yang dirancang khusus untuk membahas tentang pengetahuan kelautan. Kepingan kecil materi yang menunjang literasi kelautan tersebar pada mata pelajaranpelajaran yang bersinggungan, seperti fisika, biologi dan geografi [18]. Namun di dalamnya materi ini juga tidak dibahas secara mendetail. Sehingga dapat dikatakan warga negara Indonesia tidak pernah mendapatkan pembekalan tentang kelautan selama mengikuti pendidikan di bangku sekolah. Maka tidak heran apabila peserta didik dan masyarakat luas di Indonesia kurang memiliki pengetahuan dan kecintaan terhadap laut.

Merujuk pada apa yang telah dipaparkan, maka perlu dilakukan pengembangan media pembelajaran yakni pengembangan buku pengayaan dan Augmented Reality. Pengembangan buku pengayaan dan Augmented Reality ini diharapkan dapat memberikan dampak positif untuk meningkatkan kemampuan berpikir kritis peserta didik. Oleh sebab itu, Penulis merencanakan untuk mengembangkan buku pengayaan pengetahuan fisika bertemakan Fisika Kelautan berbasis Augmented Reality. Buku tersebut diperuntukkan bagi jenjang pendidikan menengah atas, yang dibahas sesuai dengan tingkat berpikir mereka terkait dengan penerapan konsep dasar fisika. Selain itu juga dapat dijadikan salah satu bahan ajar dalam program pengayaan di sekolah sehingga mampu meningkatkan kemampuan berpikir kritis peserta didik. 


\section{METODOLOGI}

Pada penelitian kali ini, metode penelitian yang digunakan adalah Formative Development Methods (FODEM) atau yang biasa disebut pula penelitian pengembangan [19]. Metode pengembangan formatif (FODEM) merupakan pendekatan untuk mendukung desain dan pengembangan berbagai jenis inovasi teknologi pendidikan, seperti alat belajar, dan program belajar secara online. Struktur dari metode ini memberikan fleksibilitas pada proses desain [20]. Sebagai metode formatif yang menekankan orientasi penelitian dan evaluasi melalui seluruh proses pengembangan, artikel ini mengusulkan bahwa FODEM pada dasarnya juga merupakan metode penelitian dan pengembangan. FODEM dapat digunakan untuk mengelola, menganalisis, dan memvisualisasikan proses desain keseluruhan pada berbagai tahap. Adapun desain metodologi yang dikembangkan pada penelitian ini adalah seperti pada GAMBAR 1.

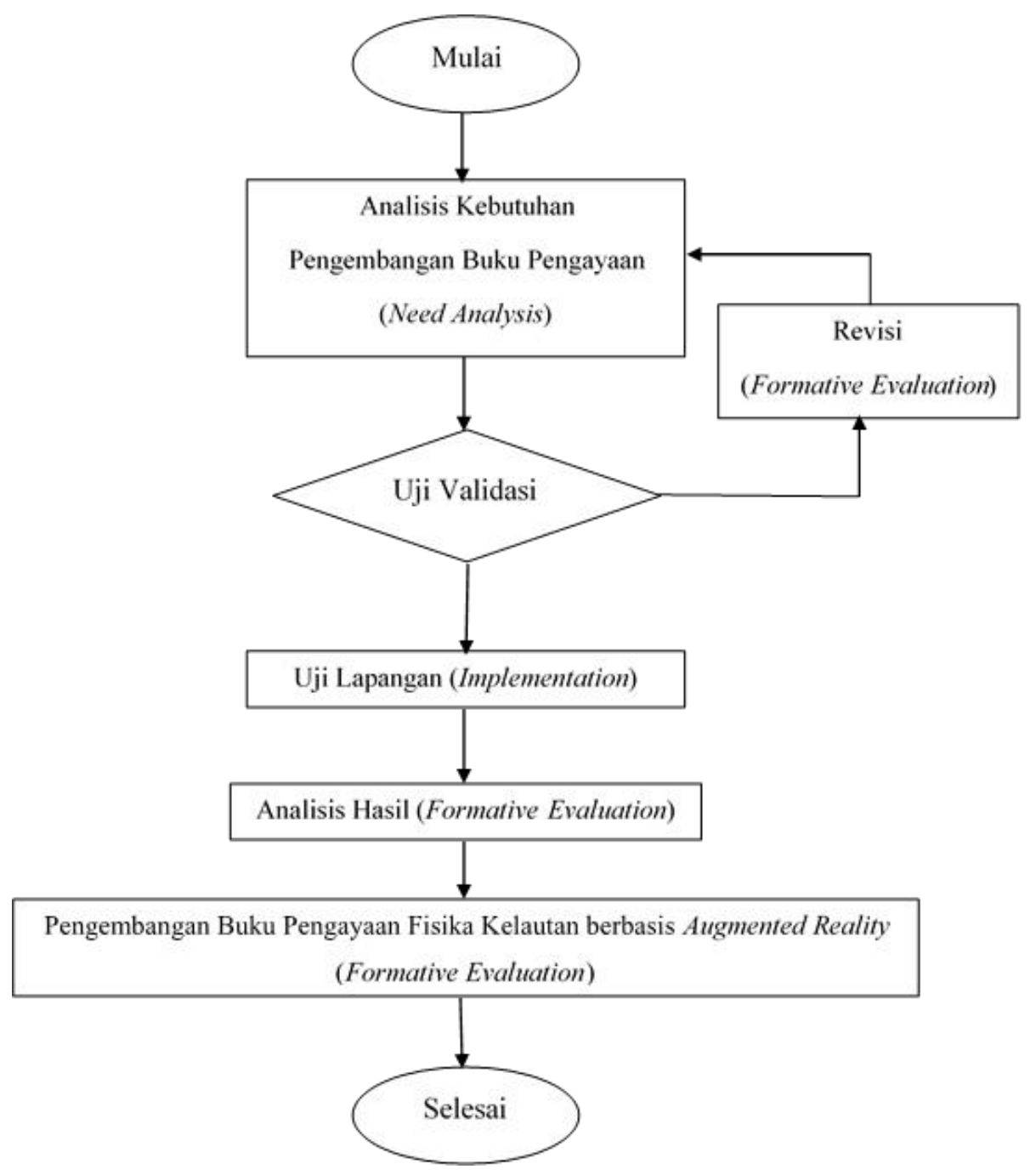

GAMBAR 1. Desain metodologi yang akan digunakan.

\section{HASIL DAN PEMBAHASAN}

\section{Buku Pengayaan Fisika Kelautan}

Buku Pengayaan yang dihasilkan memiliki pokok bahasan mengenai Fisika Kelautan. Buku pengayaan ini memuat informasi kelautan yang berhubungan dengan Fisika serta berkaitan dengan materi Fisika, rangkuman materi yang berisi inti-inti dari setiap bab, dan latihan evaluasi yang dikemas dalam bentuk permainan ular tangga agar lebih menarik. Soal yang berbasis High Order 
Thinking (HOTS) dengan tujuan untuk melatih kemampuan berpikir kritis. Buku Fisika Kelautan ini juga dilengkapi dengan gambar, animasi dan video yang dibantu dengan Augmented Reality untuk menampilkan beberapa 2D ke dalam bentuk 3D secara real-time.

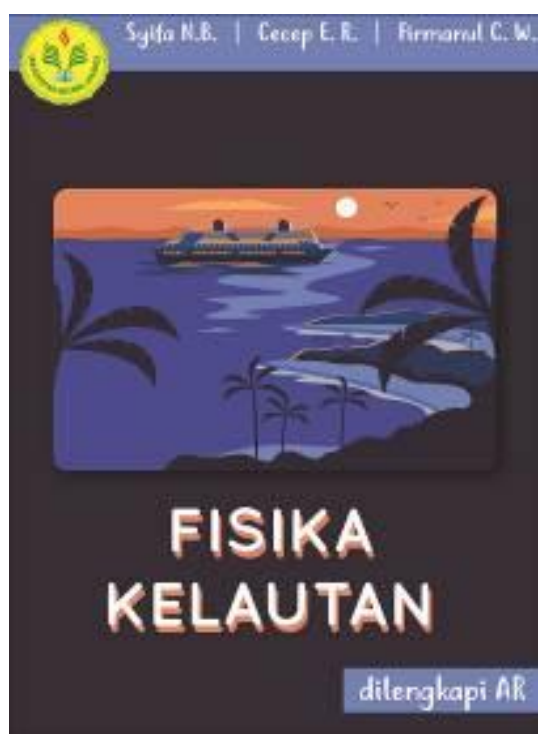

(a)

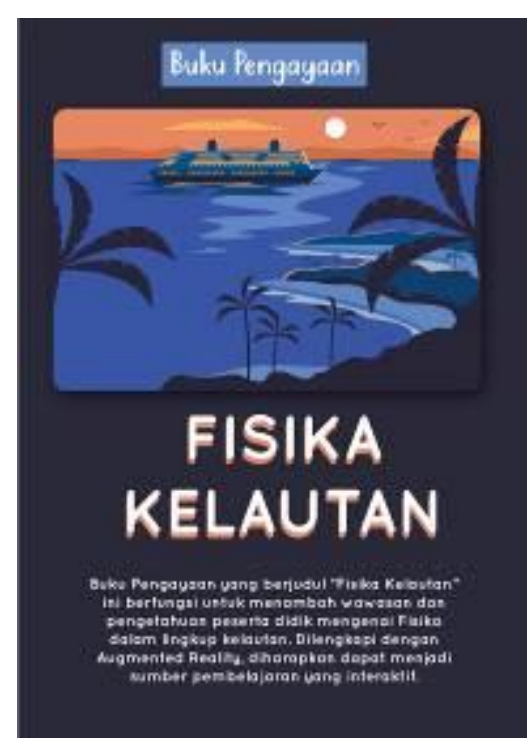

(b)

GAMBAR 2. (a) Tampilan sampul depan buku, (b) Tampilan sampul belakang buku

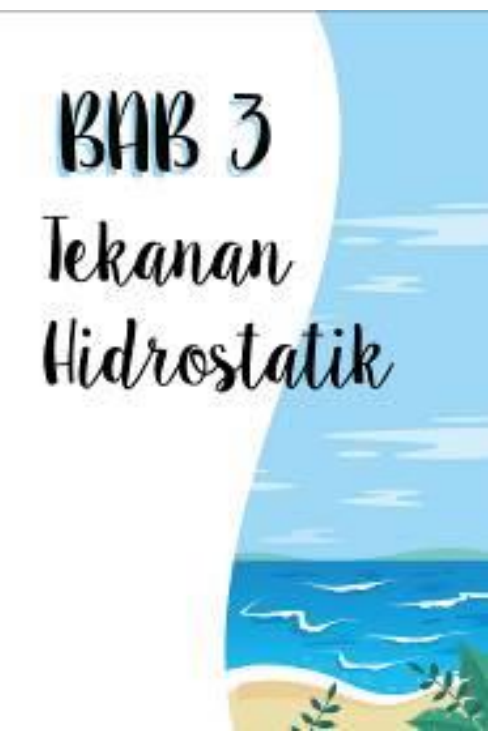

(a)
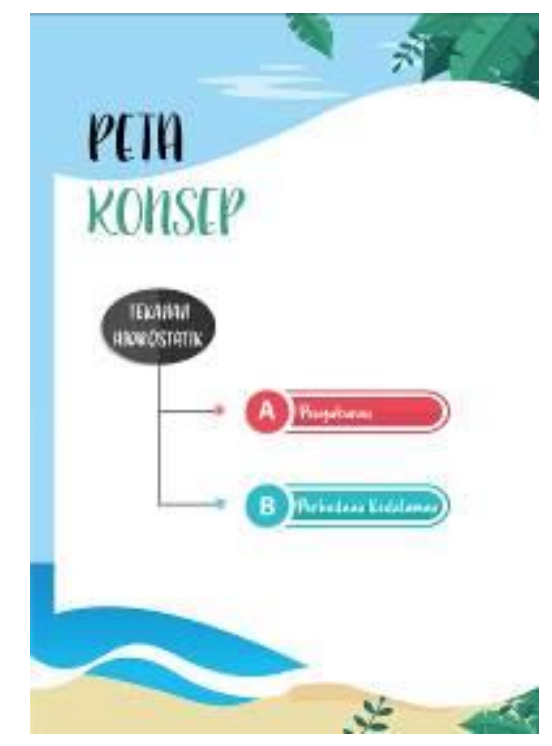

(b)

GAMBAR 3. (a) Tampilan sampul bab buku, (b) Tampilan peta konsep 


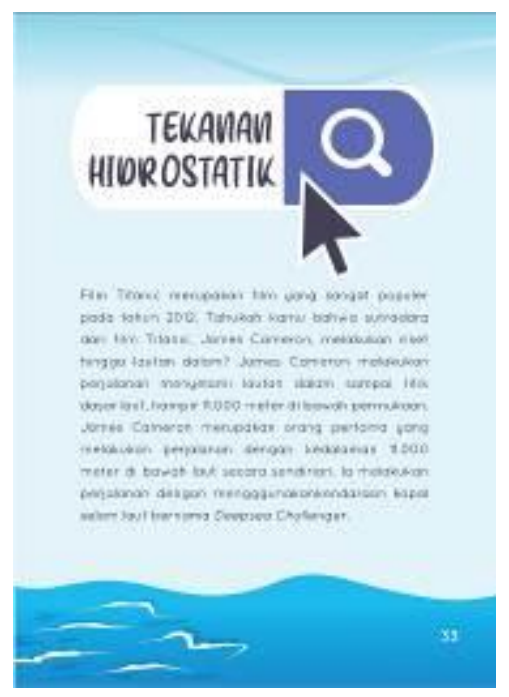

(a)

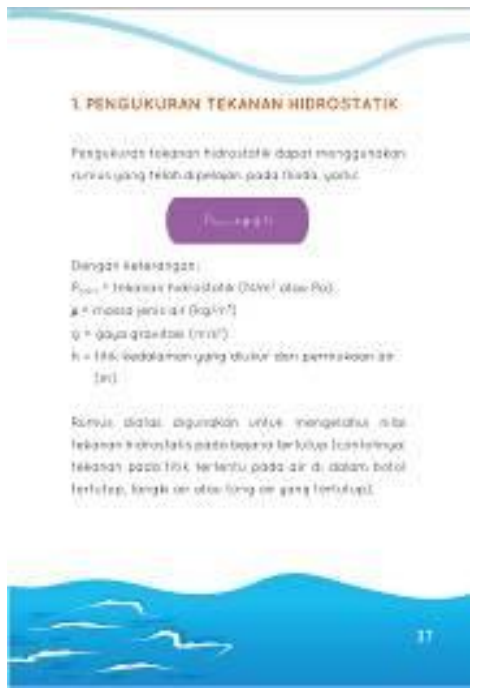

(b)

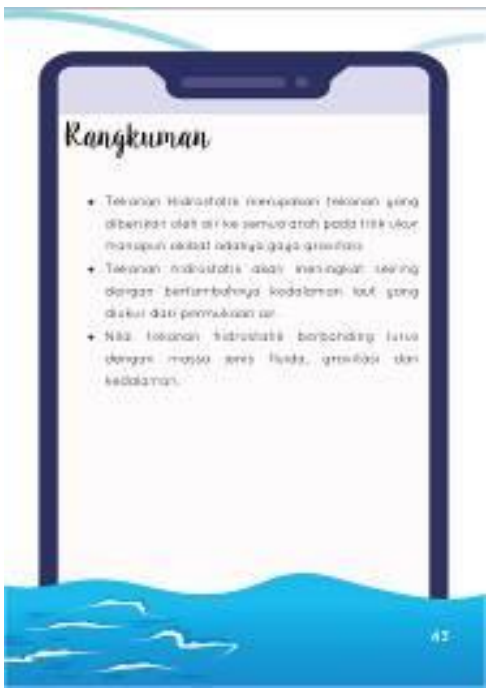

(c)

GAMBAR 4. (a) Tampilan awal pendahuluan buku, (b) Tampilan materi, (c) Tampilan rangkuman

\section{Aplikasi Augmented Reality}

Buku Fisika Kelautan yang dikembangkan ini akan memiliki beberapa gambar yang akan dijadikan marker atau penanda. Marker tersebut akan diintegrasikan dengan informasi Augmented Reality yang telah diprogram. Ketika marker dipindai, maka layar smartphone akan menampilkan animasi tiga dimensi secara real-time. Pemindaian marker dilakukan dengan bantuan aplikasi yang terpasang di smartphone. Jenis smartphone yang digunakan bisa berupa Android dengan minimal versi 4.1 (Jelly Bean) dan iOS dengan minimal versi iOS 10.

Cara penggunaan aplikasi ini adalah dengan mengarahkan kamera pada aplikasi guna memindai marker yang terdapat dalam buku. Selanjutnya, kamera akan menampilkan informasi virtual berupa animasi tiga dimensi ataupun video tiga dimensi secara real-time. Aplikasi ini memiliki interface dengan berbagai fungsi. Pertama, terdapat menu "HINT" yang berisikan petunjuk pemakaian aplikasi. Kedua, terdapat menu "SCAN ME" yang merupakan kamera untuk memindai gambar. Ketiga, terdapat menu "BOOK IN HERE" yang digunakan apabila pengguna ingin mengunduh sendiri buku pengayaan Fisika Kelautan. Keempat, "ABOUT" yang merupakan halaman yang berisi keterangan mengenai aplikasi. Terakhir, terdapat menu "HELP" yang merupakan halaman bantuan apabila mengalami kendala saat mengoperasikan aplikasi.

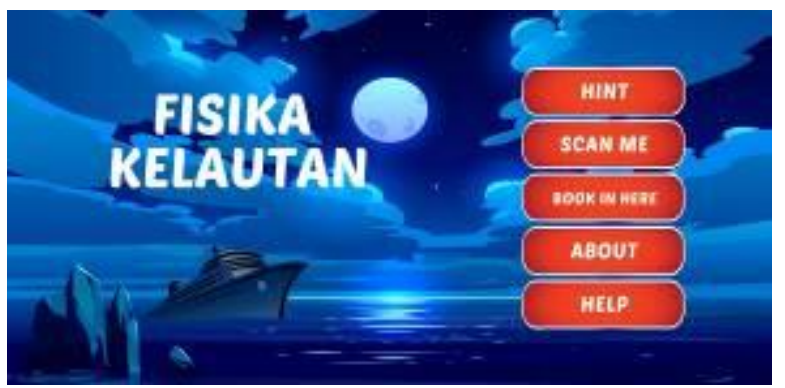

(a)

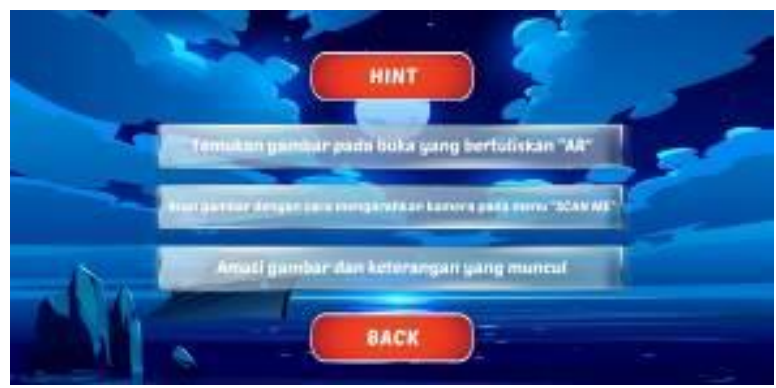

(b) 


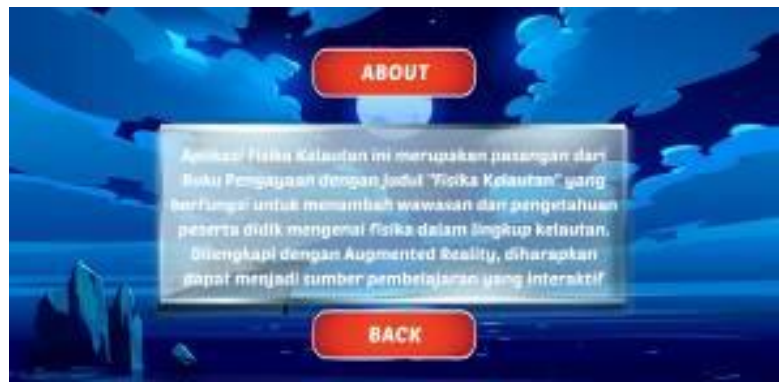

(c)

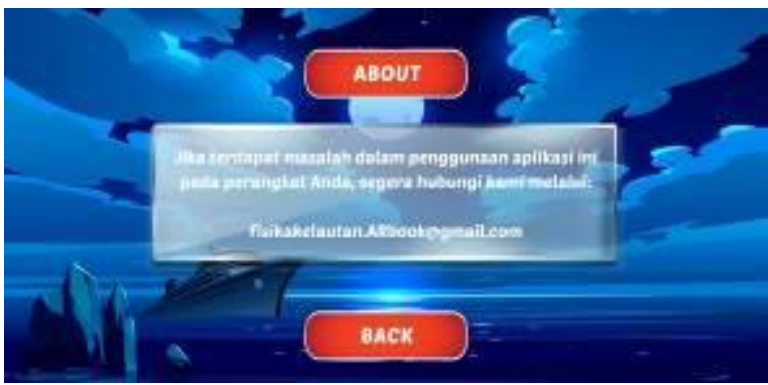

(d)

GAMBAR 5. Tampilan aplikasi yang dikembangkan (a) Tampilan awal aplikasi, (b) Tampilan menu "HINT”, (c) Tampilan menu "ABOUT", (d) Tampilan menu "HELP"

\section{SIMPULAN}

Buku Pengayaan Fisika Kelautan yang dikembangkan ini dilengkapi dengan teknologi Augmented Reality yang dapat meningkatkan kemampuan berpikir kritis peserta didik. Teknologi Augmented Reality pada buku Fisika Kelautan ini menampilkan animasi dan video dalam bentuk tiga dimensi yang dapat dianalisis oleh peserta didik untuk meningkatkan kemampuan berpikir kritis.

\section{UCAPAN TERIMAKASIH}

Terimakasih kepada seluruh pihak yang telah membantu dalam pembuatan Buku Pengayaan Fisika Kelautan ini. Terimakasih pula kepada seluruh pihak yang telah memberikan kritik serta saran dalam proses pembuatan Buku Pengayaan Fisika Kelautan yang dilengakpi oleh Augmented Reality ini. Kritik dan saran yang diberikan sangat bermanfaat dalam pembentukan buku ini.

\section{REFERENSI}

[1] L. Setiono, "Membangun Media Pembelajaran," 2009.

[2] S. Nurazizah, P. Sinaga, and A. Jauhari, "Profil Kemampuan Kognitif dan Keterampilan Berpikir Kritis Siswa SMA pada Materi Usaha dan Energi", JPPPF (Jurnal Penelitian dan Pengembangan Pendidikan Fisika), vol. 3, no. 2, pp. 197 - 202, Dec. 2017.

[3] Y. R. Denny, I. S. Utami, S. Rohanah, and D. Muliyati, "The Development of Blended Learning Model using Edmodo to Train Student Critical Thinking Skills on ImpulseMomentum Topic", JPPPF (Jurnal Penelitian dan Pengembangan Pendidikan Fisika), vol. 6, no. 1, pp. 113 - 120, Jun. 2020.

[4] Zubaidah, "Keterampilan Abad Ke-21: Keterampilan yang Diajarkan Melalui Pembelajaran," Kalimantan Barat: STKIP Persada Khatulistiwa Sintang, 2016.

[5] F. C. Wibowo, E. Budi \& L. A. Sanjaya, "Development of the Innovative Smart Orbital (ISO) Mediumto Improve the Cognitive Skillson the Heat Transfer Concept," International Journal of Learning, Teaching and Educational Research, vol. 19, no. 5, pp. 141-152, 2020.

[6] Masnur Muslich, "Text Book Writing: Dasar-Dasar Pemahaman, Penulisan, dan Pemakaian Buku Teks,” Yogyakarta: Ar-Ruzz Media, 2010.

[7] A. H. Qudwatunna, "Perancangan Ilustrasi Untuk Buku Ensiklopedia Tentang Gunung Meletus,” Disain Komunikasi Visual, 2019.

[8] Pusat Kurikulum dan Perbukuan, "Pedoman Penilaian Buku Nonteks Pembelajaran," Jakarta: Badan Penelitian dan Pengembangan Kementerian Pendidikan dan Kebudayaan, 2018.

[9] Bitter, Gary, and Allen Corral, "The Pedagogical Potential Of Augmented Reality Apps," in International Journal of Engineering Science Invention, vol. 3, no. 10, pp. 13-17, 2014. 
[10] D. Ambarwulan and D. Muliyati, "The Design of Augmented Reality Application as Learning Media Marker-Based for Android Smartphone", JPPPF (Jurnal Penelitian dan Pengembangan Pendidikan Fisika), vol. 2, no. 1, pp. 73 - 80, Jun. 2016.

[11] R. T. Azuma, "A Survey of Augmented Reality," (Presence: Teleoperators and Virtual Environments), pp. 1-3, 1997.

[12] Su Cai, "Applications Of Augmented Reality-Based Natural Interactive Learning In Magnetic Field Instruction," pp. 778-791, 2017.

[13] F. Bakri, Dadan Sumardani and Dewi Muliyati, "Integrating augmented reality into worksheets: Unveil learning to support higher-order thinking skills," in AIP Conference Proceedings," vol. 2169, no. 1, AIP Publishing LLC, 2019.

[14] F. Bakri, Ervina Ervina and Dewi Muliyati, "Practice the higher-order thinking skills in optic topic through physics worksheet equipped with augmented reality," In AIP Conference Proceedings," vol. 2169, no. 1, AIP Publishing LLC, 2019.

[15] F. Bakri, B. Z. Siahaan, and A. H. Permana, "Rancangan Website Pembelajaran Terintegrasi dengan Modul Digital Fisika Menggunakan 3D PageFlip Professional", JPPPF (Jurnal Penelitian dan Pengembangan Pendidikan Fisika), vol. 2, no. 2, pp. 113 - 118, Dec. 2016.

[16] H. Hermansyah, Gunawan and Herayanti, "Pengaruh Penggunaan Laboratorium Virtual Terhadap Penguasaan Konsep Dan Kemampuan Berfikir Kreatif Siswa Pada Materi Getaran Dan Gelombang," in Jurnal Pendidikan Fisika dan Teknologi, vol. 2, no. 1, pp. 97-102, 2015.

[17] B. Irawan, "Framework Literasi Kelautan Sebagai Acuan Pembelajaran Sains di Negara Maritim," in Pedagogi Hayati, vol. 2, no. 1, pp. 14-23, 2018.

[18] C. Cudaback, "Ocean Literacy, There's More To It Than Content," in Oceanography Journal, 21st ed, pp. 10-11, 2008.

[19] J. Suhonen, M. R. de Villiers \& E. Sutinen, "FODEM: A Multi-Threaded Research and Development Method for Educational Technology," in Educational Technology Research and Development, vol. 60, no. 2, pp. 287-305, 2012.

[20] G. D. Putra, A. Samsudin \& D. Saepuzaman, "Computer Simulation-Assisted Conceptual Change Text (CS-CCT): A FODEM Study On Fluid Dynamics," in Journal of Physics: Conference Series, vol. 1280, no. 5, p. 052045, IOP Publishing, 2019. 
